\title{
Metacarpophalangeal Arthrodesis with Resection-suspension Arthroplasty in First Carpometacarpal Osteoarthritis
}

\section{Artrodesis metacarpofalángica asociada con artroplastia de resección-suspension en rizartrosis}

\author{
Jose A. Oteo-Maldonado ${ }^{10}$ Patricia Merino-Carretero ${ }^{1}$ \\ ${ }^{1}$ Orthopedic Surgery and Traumatology Service, Hospital \\ Universitario de Fuenlabrada, Madrid, Spain \\ Address for correspondence Jose A. Oteo-Maldonado, PhD, Servicio \\ de Cirugía Ortopédica y Traumatología, Hospital Universitario de \\ Fuenlabrada, 28942 Fuenlabrada, Madrid, Spain \\ Rev Iberam Cir Mano 2020;48:27-30. \\ (e-mail: oteom@yahoo.com).
}

\section{Abstract \\ Keywords \\ - metacarpophalangeal hyperextension \\ - first carpometacarpal osteoarthritis}

\section{Resumen}

\section{Palabras Clave}

- hiperextensión metacarpofalángica

- primera osteoartritis carpometacarpiana
First carpometacarpal joint osteoarthritis (CMC-1) may develop first metacarpophalangeal joint hyperextension (MCP-1). We enrolled patients with CMC-1 osteoarthritis and MCP-1 hyperextension $\geq 40$ degrees treated with resection-suspension arthroplasty and MCP-1 intramedullary arthrodesis with $\mathrm{XMCP}^{\mathrm{TM}}$ system. Minimum follow-up was five years. We evaluated: thumbinterphalangeal (IP) range ofmotion, key pinch, hand grip, Kapandji, VAS and Quick DASH. Wilcoxon test was uses for statistical analysis.

Nineteen patients were reviewed. We found improvement in key pinch, hand grip, VAS and Quick DASH; statistical difference $(p<0.05)$ was observed in all of them except key pinch. IF thumb range of motion and Kapandji decreased.

TMC arthrodesis with $\mathrm{XMCP}^{\mathrm{TM}}$ system associated with resection-suspension arthroplasty, as a treatment for CMC-1 osteoarthritis and MCP- 1 hyperextension $\geq 40$ degrees, achieves good functional results in the medium term.

La artrosis trapeciometacarpiana (TMC) puede desarrollar hiperextensión de la articulación metacarpofalángica (MCF) del pulgar. Presentamos nuestra relación de pacientes revisados con artrosis TMC e hiperextensión MCF 40 grados asociada, tratados con artroplastia de resección-suspensión más artrodesis MCF con el sistema XMCP.

El seguimiento mínimo fue de cinco años. Se analizó: arco de movilidad interfalángica (IF) del pulgar, fuerza de pinza y de puño, Kapandji, EVA y Quick DASH. El test de Wilcoxon fue empleado para el estudio estadístico.

Se analizaron 19 casos. Hubo mejoría en los parámetros de fuerza de pinza y de puño, EVA y Quick DASH; siendo esta diferencia, estadísticamente significativa en todos ellos salvo en la fuerza de pinza. Los valores de arco de movilidad IF del pulgar y Kapandji disminuyeron.

La artrodesis MCF con el sistema XMCP asociada a artroplastia de resección-suspensión, como tratamiento de la rizartrosis cuando hay hiperextensión MCF $40^{\circ}$ grados asociada, consigue buenos resultados funcionales a medio plazo. received

March 17, 2020

accepted

March 23, 2020
DOI https://doi.org/

10.1055/s-0040-1712092. ISSN 1698-8396.
Copyright $\odot 2020$ Thieme Revinter

Publicações Ltda, Rio de Janeiro, Brazil
License terms

(ㄷ) (i) $\ominus$ (5) 


\section{Introduction}

Hyperextension of the first metacarpophalangeal joint (MCP-1) is frequently associated with first carpometacarpal joint (CMC-1) osteoarthritis, especially in its more advanced stages. ${ }^{1,2}$ Failure to adequately treat the MCP-1 joint when the trapezius is resected can lead to worsening hand function and require a reoperation. ${ }^{3}$

This study aims to determine if the simultaneous surgical treatment of both joints results in adequate clinical and functional outcomes in the medium term.

\section{Material and Methods}

This is a descriptive study. Patients who underwent surgery in our Center between January 2013 and October 2014 (minimum follow-up period of five years) with CMC-1 osteoarthritis associated with hyperextension of the MCP-1 joint have been reviewed. Inclusion criteria comprised of a history of CMC-1 joint pain that requiring scheduled treatment with analgesic agents, trapezial radiological damage classified as Eaton grade IV, CMC- 1 joint extension $\geq 40^{\circ}$ and lack of response after six month of non-surgical therapy (steroids infiltration, rehabilitation, occupational therapy). Cases with infection, fracture or previous hand surgery were excluded.

All the patients were operated on at the Upper Limb Unit with the following technique: first, the MCP-1 joint was approached and fixed with a intermedullary interlocking screws system (XMCP, Extremity Medical, Parsippany, MJ) at a $25^{\circ}$ angle, leaving the phalanx in neutral position. Next, the CMC-1 joint was accessed through a modified BurtonPellegrini technique, with complete trapezial resection and MCP-1 stabilization through a flexor carpi radialis (FCR) hemitendonplasty. Postsurgical immobilization was performed with a forearm splint including the thumb; interphalangeal joint mobilization was allowed after 3 weeks splint was removed, the use of the thumb in daily living activities was recommended, and the patient was referred for rehabilitation. Strengthening hand movements were allowed once MCP-1 joint consolidation was achieved (-Figures 1 and 2).

In addition to age, gender, side and dominance, the following data were taken before surgery and five years after the procedure: thumb interphalangeal joint (IP) range of motion, key pinch, hand grip and Kapandji, visual analog scale (VAS) and Quick Disability of Arm, Shoulder and Hand (DASH) scores. For statistical analysis, the Wilcoxon test, a non-parametric test, was used to compare pre- and postoperative values.

At the radiological level, MCP-1 arthrodesis consolidation and the absence of shock between MCP-1 and the scaphoid bones were assessed.

\section{Results}

Twenty-three patients were operated on during the study; since four of them were not located for the five-year followup evaluation, 19 cases were reviewed, including two men

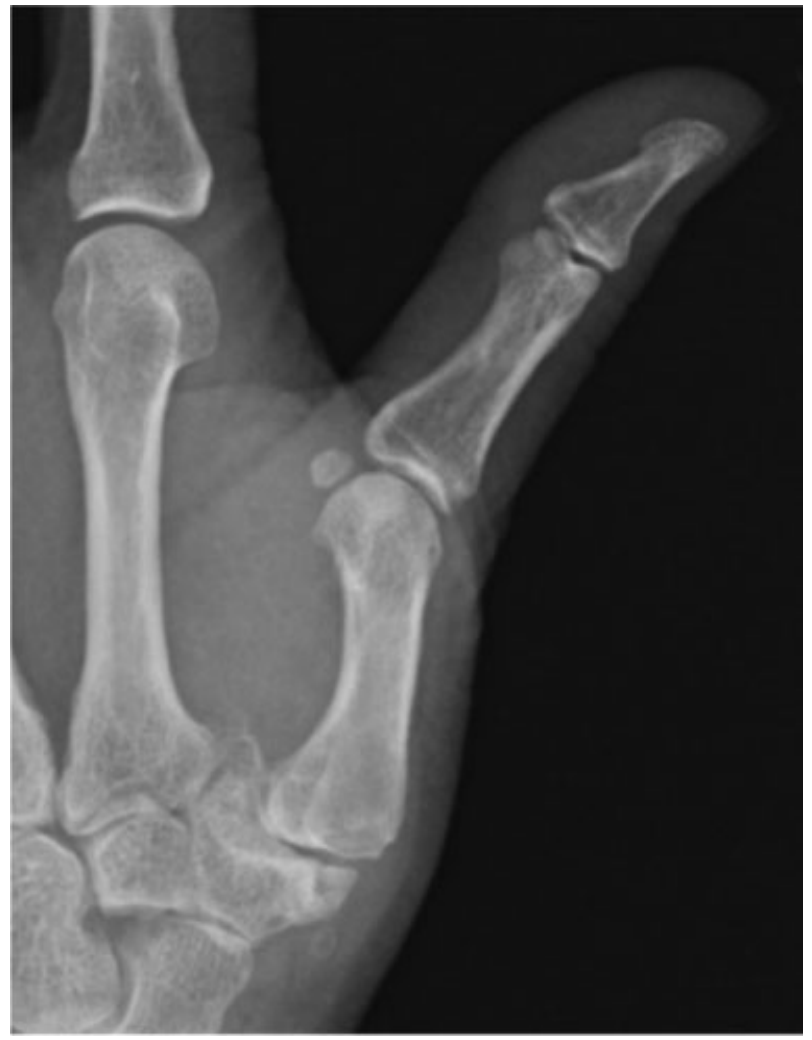

Fig. 1 Preoperative radiograph.

and 17 women, with seven right and 12 left sides, and seven dominant and 12 non-dominant hands.

Measured variables are shown in -Table 1.

All cases presented MCP-1 arthrodesis consolidation without any problems related with the osteosynthesis material. No shock between MCP-1 and the scaphoid bones was noted, and there was always a space between such bones.

\section{Discussion}

Patients operated on for first carpometacarpal osteoarthritis require a detailed examination of the hand, especially of the thumb bone. MCP-1 dorsoradial subdislocation in relation to the trapezius can result in its flexion and adduction; as the intermetacarpal space narrows, the MCP-1 joint hyperextends to grasp and apprehend objects. Similarly, thumb IP joint flexion increases, leading to a zig-zag deformity. ${ }^{1,2}$

There is no superior technique for first carpometacarpal osteoarthritis treatment. ${ }^{4}$ It is known that the surgical correction of a MCP-1 hyperextension of less than $30^{\circ}$ simultaneously to the trapezius surgery does not result in an objective benefit, since extension an improve with CMC-1 subdislocation correction. ${ }^{2,5}$ However, it is also known that trapezius resection (associated or not with CMC-1 suspension) can worsen hyperextension MCP-1 because it decreases the height of the thumb bone. ${ }^{3}$ This does not happen if the trapezius is spared after CMC- 1 reduction, as when a CMC- 1 prosthesis is used. ${ }^{6}$ Hyperextension MCP-1 alone or associated with a shock between MCP-1 and the carpal remnant is a cause of trapeziectomy revision. ${ }^{7,8}$ 


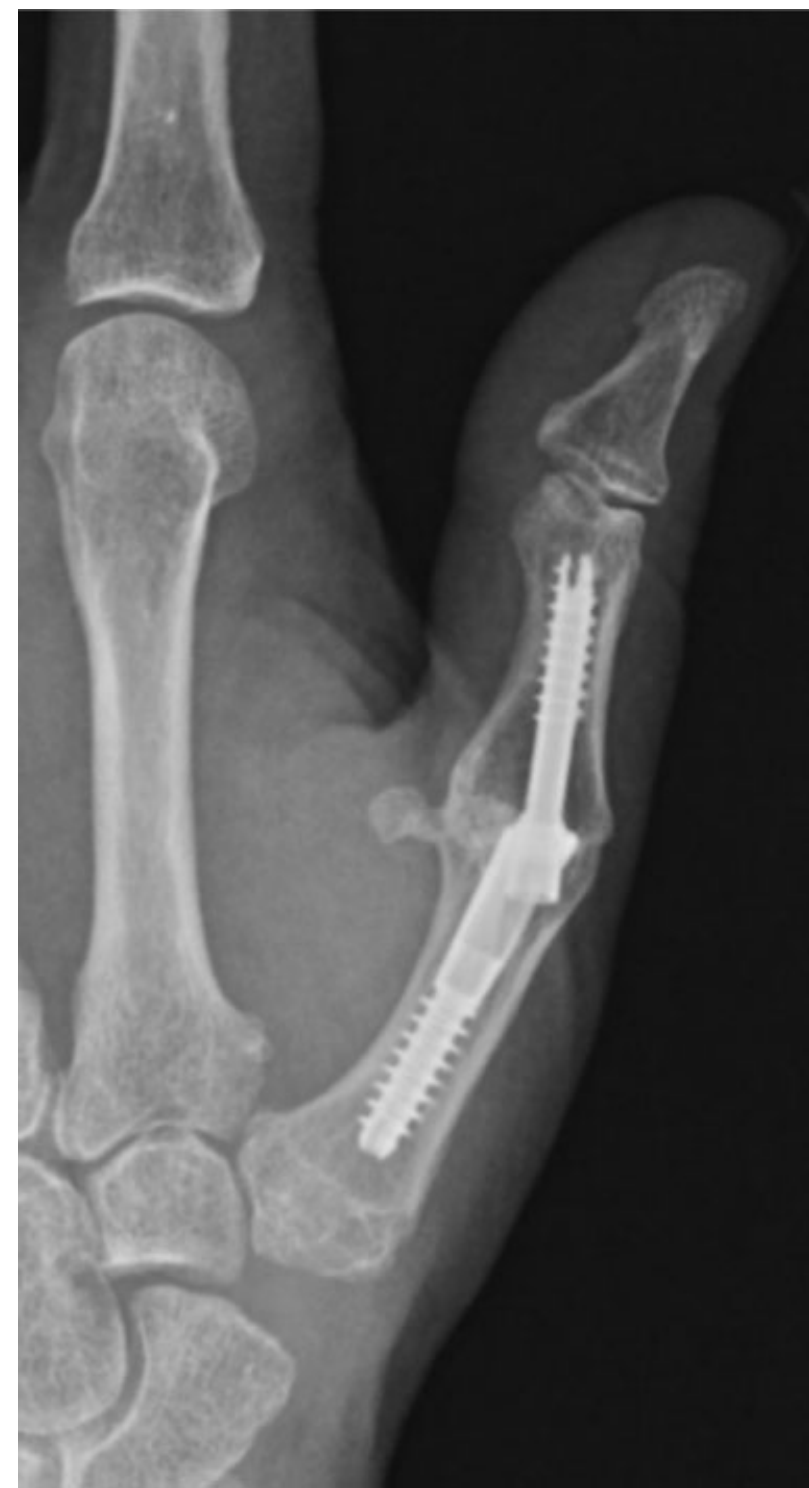

Fig. 2 Postoperative radiograph (five-year follow-up).

The MCP-1 joint must be treated concurrently to the CMC1 joint to avoid revision surgeries. Different combined surgical techniques have been proposed when hyperextension exceeds $30^{\circ}$, including needle temporary fixation (with poor outcomes year), volar capsulodesis, proximal and radial transfer of the extensor pollicis brevis (EPB) to MCP-1, sesamoids fusion (leading to the loss of $8^{\circ}$ in extension) or MCP-1 arthrodesis. ${ }^{5,9}$

Capsulodesis combined with trapezius resection results in tension loss over time. Miller states that hyperextension goes from $19^{\circ}$ one year after surgery to $30^{\circ} 9$ years after the procedure, with thumb flexion preservation but no pain. ${ }^{10}$ De Smet compared MCP-1 capsulodesis and arthrodesis with trapeziectomy outcomes and reported no clinical differences, indicating that this finding was possibly due to the small sample size. ${ }^{11}$

Some authors only recommend MCP- 1 arthrodesis in case of recurrence or if the patient is symptomatic; ${ }^{9}$ others, ${ }^{2}$ however, indicate its performance when joint extension exceeds $40^{\circ}$ (a criterion followed by these authors) because, although mobility is sacrificed, it provides a stable column that is very important for hand function. ${ }^{5}$ Different surgeries have been proposed to do so, including the use of needles with or without cerclage, screws and plates. ${ }^{5}$ We opted for a system with intramedullary screws at a fixed angle of $25^{\circ}$ that allowed early mobilization and resulted in fusion in all cases, without the problems related to the osteosynthesis material (especially adhesions or the need to remove them) which had already been noted in previous studies with this device. ${ }^{12,13}$

There is controversy on how to perform the osteosynthesis between the phalanx and the metacarpal bone during MCP-1 arthrodesis to achieve a better thumb function. If not combined with a trapezius resection, it is recommended to leave it in pronation; ${ }^{8,14}$ since trapezius removal leads to metacarpal bone pronation and abduction, phalanx stabilization in a slight supination was proposed to achieve better stability for key pinch. ${ }^{2}$ In our study, we decided to leave the phalanx in a neutral position because it is the most comfortable with the system used.

Regarding measured variables, thumb IP joint range of motion and Kapandji score was deemed suitable for the function of the hand, but decreased, possibly due to the new position of the MCP- 1 joint. There were no statistically significant changes in key pinch, but hand grip increased significantly. Final key pinch, hand grip and Kapandji score values are very similar to those from a previously published series with trapeziectomy alone. ${ }^{15}$ VAS and Quick DASH scores showed that pain and quality of life, respectively, improved significantly, even considering that subjective

Table 1 Pre- and postoperative values (five years after the procedure)

\begin{tabular}{|c|c|c|c|}
\hline & $\begin{array}{l}\text { PREOPERATIVE VALUE } \\
\text { ( } \pm \text { standard deviation) }\end{array}$ & $\begin{array}{l}\text { POSTOPERATIVE VALUE } \\
\text { ( } \pm \text { standard deviation) }\end{array}$ & $P$ \\
\hline Thumb interphalangeal range of motion & $73.15^{\circ}( \pm 7.49)$ & $53.95^{\circ}( \pm 22.94)$ & 0.001 \\
\hline Key pinch & $4.18 \mathrm{~kg}( \pm 1.73)$ & $4.79 \mathrm{~kg}( \pm 1.53)$ & 0.202 \\
\hline Hand grip & $16.99 \mathrm{~kg}( \pm 9.04)$ & $21.92 \mathrm{~kg}( \pm 6.21)$ & 0.007 \\
\hline Kapandji score & $9.17( \pm 1.38)$ & $8.21( \pm 1.32)$ & 0.103 \\
\hline Visual analog scale score & $8.59( \pm 0.67)$ & $1.42( \pm 1.8)$ & 0.000 \\
\hline Quick DASH score & $71.91( \pm 6.96)$ & $20.63( \pm 14.83)$ & 0.000 \\
\hline
\end{tabular}

DASH, Disability of Arm, Shoulder and Hand. 
factors influence treatment outcomes. ${ }^{16}$ De Smet indicates that patients with CMC-1 osteoarthritis and MCP-1 hyperextension have less pain after treatment of both joints. ${ }^{11}$

Our study had several handicaps, including the small sample size and the lack of a control group with first carpometacarpal osteoarthritis plus hypermobility and treated with resection arthroplasty alone.

Despite these limitations, MCP-1 arthrodesis with XMCP combined with trapezius resection, ligament reconstruction and tendon interposition have good outcomes both for hand function and quality of life in the medium term. This arthrodesis system results in seamless fusion with no problem associated.

Conflict of Interests

The authors have no conflict of interests to declare.

\section{References}

1 Lourie GM. The role and implementation of metacarpophalangeal joint fusion and capsulodesis: indications and treatment alternatives. Hand Clin 2001;17(02):255-260

2 Dumont CE, von Campe A. Benefits of additional procedures for metacarpophalangeal hyperextension on simple trapeziectomy in thumb basas osteoarthritis: A biomechanical cadaver study. J Hand Surg Asían Pac. 2019;24(02):159-160

3 Robles-Molina MJ, López-Caba F, Gómez-Sánchez RC, CárdenasGrande E, Pajares-López M, Hernández-Cortés P. Trapeziectomy with ligament reconstruction and tendon interposition versus a trapeziometacarpal prosthesis for the treatment of thumb basal joint osteoarthritis. Orthopedics [Internet]. 2017 [Consultado: 9 de marzo de 2020];40(4):e681-e686. Disponible en: https:// www.healio.com/orthopedics/journals/ortho/2017-7-40-4/\% 7B9ac71304-5fb6-42f9-9ef7-6cd196d51a58\%7D/trapeziectomywith-ligament-reconstruction-and-tendon-interpositionversus-a-trapeziometacarpal-prosthesis-for-the-treatment-ofthumb-basal-joint-osteoarthritis\#divReadThis

4 Sajon A, Vinycomb T, Carr E, Edmundo I, Ada L. WITHDRAWN: Surgery for thumb (trapeziometacarpal joint) osteoarthritis. Cochrane Database Syst Rev [Internet]. 2017 [Consultado: 9 de marzo de 2020];(4). Disponible en: https://www.ncbi.nlm.nih. gov/pmc/articles/PMC6478278/
5 Berger AJ, Meals RA. Management of osteoarthrosis of the thumb joints. J Hand Surg Am 2015;40(04):843-850

6 Mattila S, Waris E. Revision of trapeziometacarpal arthroplasty: risk factors, procedures and outcomes. Acta Orthop [Internet] 2019[Consultado: 9 de marzo de 2020];90(4):389-393. Disponible en: https://www.tandfonline.com/doi/full/10.1080/1745367 4.2019.1599253

7 Munns JJ, Matthias RC, Zarezadeh A, et al. Outcomes of revisiones for failed trapeziometacarpal joint artritis surgery. J Hand Surg Am 2019;44(09):798.e1-798.e9

8 Li J, Li D, Tian G, Zhang W. Comparison of arthrodesis and arthroplasty of Chinese thumb carpometacarpal osteoarthritis. J Orthop Surg Res [Internet]. 2019 [Consultado: 9 de marzo de 2020];14 (1):404. Disponible en: https://www.ncbi.nlm.nih.gov/pmc/articles/ PMC6884865/pdf/13018_2019_Article_1469.pdf

9 Klinefelter R. Metacarpophalangeal hyperextension deformity associated with trapezial-metacarpal arthritis. J Hand Surg Am 2011;36(12):2041-2042, quiz 2043

10 Miller NJK, Davis TR. Palmar plate capsulodesis for thumb metacarpophalangeal joint hyperextension in association with trapeziometacarpal osteoarthritis. J Hand Surg Eur Vol 2014;39(03):272-275

11 De Smet L, Vandenberghe L, Didden K, Degreef I. Outcome of simultaneous surgical treatment of hyperextension of metacarpophalangeal and basal joint osteoarthritis of the thumb. Acta Orthop Belg 2013;79(05):514-516

12 Novoa-Parra CN, Montaner-Alonso D, Morales-Rodríguez J. Artrodesis de la articulación metacarpofalángica del pulgar con tornillos intramedulares entrelazados de ángulo fijo ХMCPТМ ${ }^{\mathrm{TM}}$ Rev Esp Cir Ortop Traumatol 2018;62(05):387-391

13 Vanderzanden JC, Adams BD, Guan JJ. MCP arthrodesis using an intramedullary interlocking device. Hand (N Y) 2014;9(02): 209-213

14 Swaisi M, Igeta Y, Pavalache R, et al. Arthrodesis of the thumb metacarpophalangeal joint: Conventional open technique with a locking plate or compression pins versus minimally invasive technique with compression pins or screws. Hand Surg Rehabil 2019;38 (03):174-178

15 Marenghi L, Paterlini M, Tocco S, Corradi M. Trapeziectomy with ligament reconstruction and tendon interposition arthroplasty with the entire width of the flexor carpi radialis tendon. Tech Hand Up Extrem Surg 2016;20(02):67-70

16 Ottenhoff JSE, Teunis T, Janssen SJ, Mink van der Molen AB, Ring D. Variation in offer of operative treatment to patients with trapeziometacarpal osteoartrthritis. J Hand Surg Am 2020;45(02): 123-130.e1 